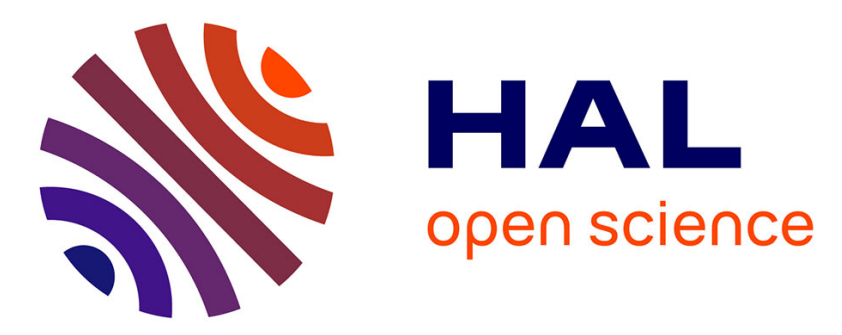

\title{
Risk assessment based on performantial criterion for inspection of offshore structures in presence of large cracks
}

Franck Schoefs, Mustapha Rguig, Alexandre Clément

\section{To cite this version:}

Franck Schoefs, Mustapha Rguig, Alexandre Clément. Risk assessment based on performantial criterion for inspection of offshore structures in presence of large cracks. Revue Européenne de Génie Civil, 2006, 10 (5), pp.531 - 547. 10.1080/17747120.2006.9692843 . hal-01007263

\section{HAL Id: hal-01007263 \\ https://hal.science/hal-01007263}

Submitted on 22 Jan 2017

HAL is a multi-disciplinary open access archive for the deposit and dissemination of scientific research documents, whether they are published or not. The documents may come from teaching and research institutions in France or abroad, or from public or private research centers.
L'archive ouverte pluridisciplinaire HAL, est destinée au dépôt et à la diffusion de documents scientifiques de niveau recherche, publiés ou non, émanant des établissements d'enseignement et de recherche français ou étrangers, des laboratoires publics ou privés.

\section{(c)(1)}

Distributed under a Creative Commons Attribution| 4.0 International License 


\section{Risk assessment based on performantial criterion for inspection of offshore structures in presence of large cracks}

\section{Franck Schoefs - Mustapha Rguig - Alexandre Clément}

GeM - Institut de Recherche en génie civil et mécanique, UMR CNRS 6183 Université de Nantes, Ecole Centrale de Nantes

Faculté de Sciences, 2 rue de la Houssinière, BP 92208, F-44322 Nantes cedex 3 franck.schoefs@univ-nantes.fr

ABSTRACT. When performing risk analysis, it is often uneasy to find the link between limit state and consequences. This paper focuses on efficiency based limit states in case of large cracks on offshore structures. Randomness and uncertainties on loading as well as on crack measurement and detection are introduced.

RÉSUMÉ. Les analyses de risque sont souvent délicates par manque de lien direct entre la fonction d'état et les conséquences. Cet article propose des fonctions d'état de type performantiel (déplacement) dans le cas d'apparitions de fissures traversantes dans des tubes métalliques de structures offshore. Les aléas sur le chargement, la mesure de la fissure et la performance des inspections sont intégrés dans l'analyse de risque.

KEYWORDS: risk assessement, through crack, offshore platform, inspection. MOTS-CLÉS : évaluation des risques, fissure traversante, plateforme offshore, inspection. 


\section{Introduction}

Nowadays reassessment of structures is a great challenge for public or private owners. In offshore field, this subject appeared in the 1990s when the platforms that were installed in the 1970s reached their initial life time of about 20 years. Most of them were steel framed structures made with welded tubular components and called Jacket platforms: they were about 2000 to be reassessed in the 1990s all over the word in various sites such as the gulf of Mexico, the gulf of Guinea and the North Sea. This challenge is still of first importance with more and more sophisticated methods such as Risk Based Inspection (Goyet et al., 2004; Rouhan et al., 2004). Owners and certification companies must provide decision aid tools to extend the life-time, with or without repairing, or to remove the structure. In this last case, the removing is a delicate and dangerous operation which includes important risks as detailed by (Kroon, 2004). We focus here on the other cases where the operator requires data up-dating (modification of the structure, metocean data, inspection results) and decision aid-tools able to include hazards and the new requirements of regulation. Deterministic approaches are not generally efficient and considered as too conservative; in fact, during reassessment it is common to compute fatigue lifetime of joints of several months when no crack occured since 30 years. That leads to state the importance of reliability and risk analysis which offers since 20 years the basic theoretical concepts to approach this complexity (Wenche et al., 2000).

In addition, they are a great amount of these structures includes an important reserve of integrity due to redundancy at design stage and and they need of simplification of building process (using of similar components to prevent human errors). Thus they are not optimized from reliability point of view and local damages may be tolerated. That's the case for through cracks, obtained when the crack depth reaches the steel thickness. Usual reliability studies (Madsen, 1997), are based on a local limit state which considers the geometry of the crack (depth or length) as critical values. The joint typology is introduced only in an implicit way when damage is computed using the Paris law. As critical values are very fair (steel thickness), these criteria are very conservative and don't allow to analyze the stress distribution in presence of cracks. One reason is that the scale effect needed to include local mechanical quantities in global structural analysis.

We suggest here a complete approach based on hybrid physical-analytical response surfaces in the aim to:

- analyze the effect of through crack on the structural analysis (Schoefs et al. 2003),

- model wave loading in storm conditions (Schoefs, 1996).

What distinguishes physical response surfaces from analytical response surfaces is the use of deterministic mechanical models. The selected structural model is based on a cracked joint finite element. In terms of a probabilistic analysis, this approach 
leads to an increase in dimension of probabilistic space which acts on reliability level if no precaution is taken (correlation, conditioning).

After the reminder of key points for risk analysis in section 2, the paper focuses in section 3 on response surface methodology and their building. It allows to provide in section 4 a parametric reliability analysis for a tripod structure: parameters are the mean crack length and its position. Performantial limit state functions are selected and based on the displacement at the top of the structure and strain energy. The paper ends in section 5 with a parametric risk based inspection of this structures when including the reliability of No Destructive Techniques: parameters introduce costs of repair, failure and inspection.

\section{Basic key points of risk estimation}

Risk estimation aims to evaluate risk " $R$ ", defined for a given event " $e$ " in Equation [1]:

$$
R=p(e) \times C(e)
$$

where $p(e)$ is the probability associated to event " $e$ " and $C(e)$ the vector of consequences due to this event.

In case of offshore platforms analysis, $p(e)$ is estimated both for exploitation (oil pipes, electrical and hydraulic systems, fire protection...) and for structure on which the present paper focuses on. Here, assessment of $p(e)$ comes from a reliability study according to a performantial state function. Components of vector $C(e)$ are generally loss of human life, financial loss of exploitation, environmental consequences in terms of biological loss (wildlife, flora) and economical (cleaning, tourist picture)... When possible, vector of consequences is reduced to only one component, sum of all homogenized components, for example under a monetary form. Otherwise, a multicriterion analysis is necessary.

\section{Physical response surfaces of loading and strength}

\subsection{Concept of physical response surface and its application}

R.S.M. has been largely developed during the last decade and response function models, including non-linear ones, are now tractable especially for the specific needs of structural reliability analysis (Labeyrie et al., 1995). This methodology is basically a formal representation based on geometrical ideas in link with a surface building in the probabilistic space. It leads to investigate properties of a physical process versus a system approach. That means the required response (e.g. mechanical behaviour) to be considered as the output of a system, which varies in 
response to the changing levels of several input variables (stimuli) called basic variables (Figure 1).

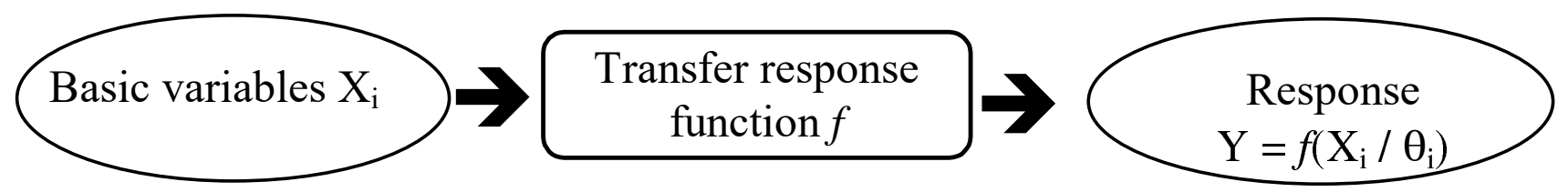

Figure 1. System modelling using response surfaces

System has to be modelled by some mathematical function of random variables $X_{i}$ involved in the system and characterised by statistical information $\theta_{i}$ (moments, free or parametric distribution functions...). For reliability analysis, the investigated response is either strength, load variables or limit state function. The surrogates to original models are classically analytical functions (mainly polynomial expression) whose parameters are estimated from experimental plans. It is to notice that these polynomial or derived functions are used as simplest readily available smoothing curves, without any appeal to their theoretical properties as asymptotic approximations to the true response function (Bouyssy et al., 1994; Muzeau et al., 1993). Such a "blind approach" allows non-intrusive reliability analysis with the use of standard finite element sofware, but it remains very questionable and limits have been already proved and illustrated (Labeyrie et al. 1995; Leira et al. 2003).

This context leads to state the importance for defining building criteria, according to the specific attempt on reliability analysis. Three major criteria, which may conflict, have been proved to be relevant by Labeyrie and Schoefs (1996):

- physical meaning, in the sense that approximation functions are based as far as possible on some understanding of the underlying mechanism of the physical process,

- distribution effects; the selection of basic variables and model fitting should reflect how the whole distribution is well transferred through the response surface (the so-called distribution effects) especially for non-linear transfer as some energetic transfers (loading of wind or wave),

- goodness of fit measurement; the metrics of the Sobolev space can be suggested to introduce some mean least squares error on the partial derivatives as a measure of the fitting goodness (Schoefs, 1996),

- computational tractability; an increase of the complexity level in stochastic modelling doesn't ensure necessarily more realistic results and is always a time consuming option when computing.

As an alternative to usual regression techniques for the fitting of model to a data base, we suggest here a building of response surfaces which respects the previous criteria. We propose to combine the stochastic modeling of basic field and deterministic transfer function. This method called physical response surface, based 
on sensitivity and uncertainty studies, allows to rank the input variables and to target the feature efforts of probabilistic modeling for the dominant random variables. This approach is self-consistent too in case of extrapolation of model once probabilistic support of basic variables stay between the physical limit bounds of the model. The illustration presented below focuses on the energetic transfer for the computing of severe wave loading (storm conditions) acting on cracked Jacket offshore structures, composed with welded steel tubular components (see Figure 2). Two response surfaces are suggested: the first one concerns the loading and the second one the components of stiffness matrix in case of crack presence.

From the resulting response surface, reliability studies based on performantial criterion (displacement or strain energy) can then be performed. The response function takes an physical analytical form in simple cases (Schoefs et al., 2005) but in complex real cases the using of Monte-Carlo simulation and finite-element model are needed to perform directly reliability computations or to fit an analytic response surface.

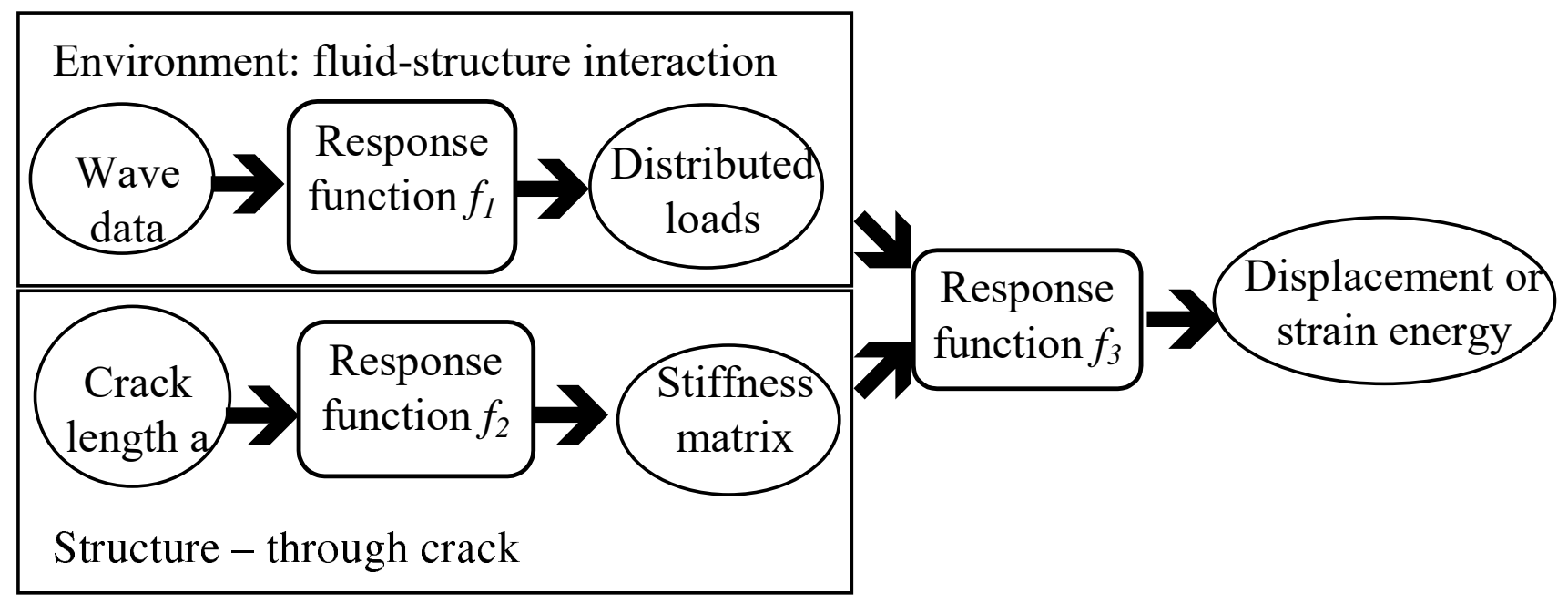

Figure 2. Response surfaces for the global problem

\subsection{Building of selected response surfaces}

Response surface of wave loading in severe storm conditions is presented in (Schoefs, 1996). The source of environmental loading resides in kinematics field of water particles near the structural component. Knowing this kinematics field, Morison equations give the distributed load on such a wet component as the summation of a drag (Equation [2]) and an inertial (Equation [3]) component (Morison et al., 1950). Equations [2] and [3] give the corresponding response surfaces.

$$
\left.\overrightarrow{f_{T}}(M)=\frac{1}{2} \rho D \theta_{m g} \sqrt{a_{(n)}^{2}+b_{(n)}^{2}}\left[\pi C_{X} \Pi_{b}+C_{D} \Pi_{b}+\right] a_{(n)} \vec{A}+b_{(n)} \vec{B}\right)
$$




$$
\left.\vec{f}_{l}(M)=\frac{1}{2} \rho \pi D^{2} \theta^{2} m g\left[C^{\prime}{ }_{x} \Pi_{b}+C_{M} \Pi_{b} \perp\right]_{c_{(n)}} \vec{A}+d_{(n)} \vec{B}\right)
$$

where $a, b$, c et $d$ are stochastic fields that depend of the set of environmental variables: extreme wave height and the wave number $k$. In the following, they are computed using the first order Stokes model where " $n$ " equals 1 (Airy waves). Coefficients $C_{X}, C_{D}, C_{M}, C_{X}^{\prime}$ allows to introduce fluid-structure interaction. The factor $\theta_{m g}$ is the increase of section diameter $D$ due to marine growth and $\rho$ is the density of fluid. Vectors $\vec{A}$ and $\vec{B}$ are orthogonal and deterministic. Operators $\Pi_{b}$ and $\Pi_{b} \perp$ denote respectively the orthogonal projection on the beam element and the projection on the orthogonal plane to the beam element.

Inspection of welding joint of offshore structures are generally practiced in harsh conditions; hazards on crack length " $a$ " as well as the capability to detect a crack (see section 5) must be taken into account. The uncertainty on measurement leads to an uncertainty in mechanical properties (geometrical) and thus to a random mechanical behavior. This randomness on geometry leads to high computation costs when using the common analytical response surface methodology associated with a finite element software (Lemaire, 1997). In fact, the well-known cost of re-meshing is then of first importance. Here we select a mixed response surface "physicalanalytical". An analytical approximation of stiffness matrix component is then deduced from simplified physical model called Cracked Joint Finite Element (CJFE). It is presented on Figure 3 in case of a crack with a plan of symmetry (here $(\mathrm{x}, \mathrm{y})$; then two parameters " $e_{y}$ " and " $k_{z}$ " are introduced.

We model the large through crack in considering the resulting loss of stiffness (two flexion springs with stiffness $k_{y}$ and $k_{z}$ ) and neutral fiber displacement in the cracked section of the beam (two eccentricities $e_{y}$ and $e_{y}$ ). Expression of these response surfaces whatever the joint typology (T-joint, K-joint...) are available in (Rguig, 2005).

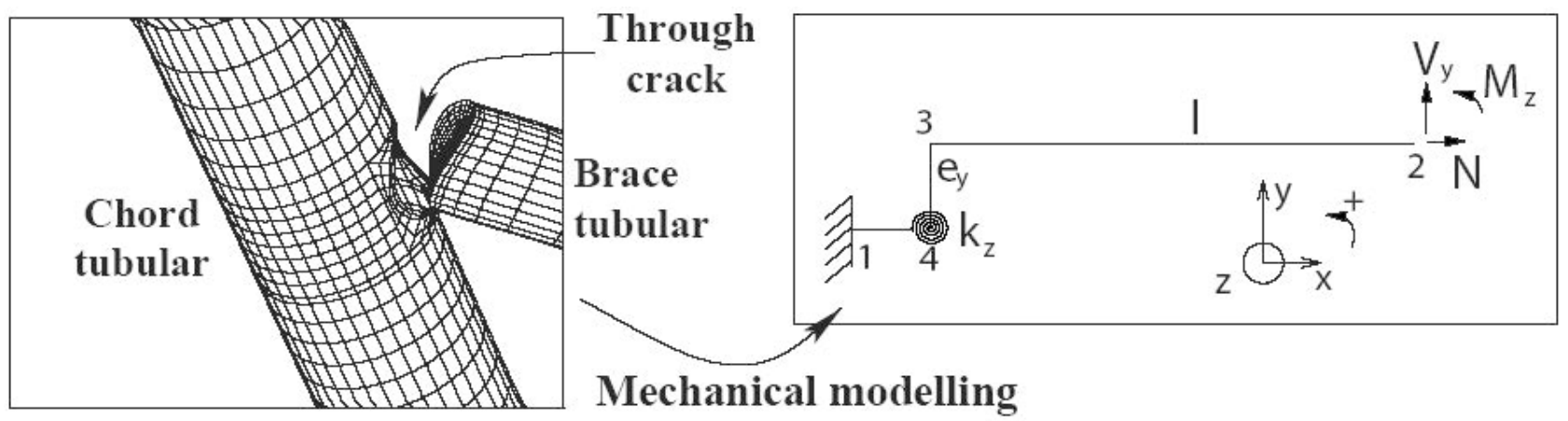

Figure 3. Cracked joint finite element (CJFE) model 


\subsection{Sensitivity analysis}

Suggested response surfaces lead to increase the dimension of the probabilistic space. In fact, space of basic random variables has a dimension of $8\left\{H, k, C_{X}, C_{D}\right.$, $C_{M}, C_{X}{ }_{X}, \theta_{m g}$, a $\}$ where $H$ and $k$ are correlated. Space of intermediate design variables, transferred through the CJFE has a dimension of $11\left\{H, k, C_{X}, C_{D}, C_{M}\right.$, $\left.C^{\prime}{ }_{X}, \theta_{m g}, e_{y}, e_{y}, k_{y}, k_{z}\right\}$ where $H$ and $k$ firstly and the set $\left(e_{y}, e_{y}, k_{y}, k_{z}\right)$ secondly are correlated. From reliability point of view, the consequence is an increase of the probability of failure. Sensitivity studies are dedicated to this question by performing Monte-Carlo simulations or perturbation techniques. A sensitiveness ratio is defined in (Rguig et al., 2005) and several sensitivity studies are available for the CJFE model alone (Schoefs et al., 2004) or in presence of extreme wave loading in the case of a wet cracked vertical component (Schoefs et al., 2005). They shown that, in the CJFE model, only stiffness plays a significant role. As a consequence, probabilistic space has a dimension of 9 even 8 in the case of low through crack size: in fact, $k_{y}$ does not act any more in this case.

\section{Reliability results on real structure}

\subsection{Description of the structure}

A tripod structure is selected for illustration (Figure 4). Some of them are used for burning non-exploited gaz of oil fields. They are generally unmanned and placed far away from coasts. An analysis only based on economical considerations can then be accepted. A beam finite element model of the studied platform is represented too on Figure 4; the water depth is about $40 \mathrm{~m}$ and the structures comprises 14 tubular components. More details are available in (Rguig, 2005).
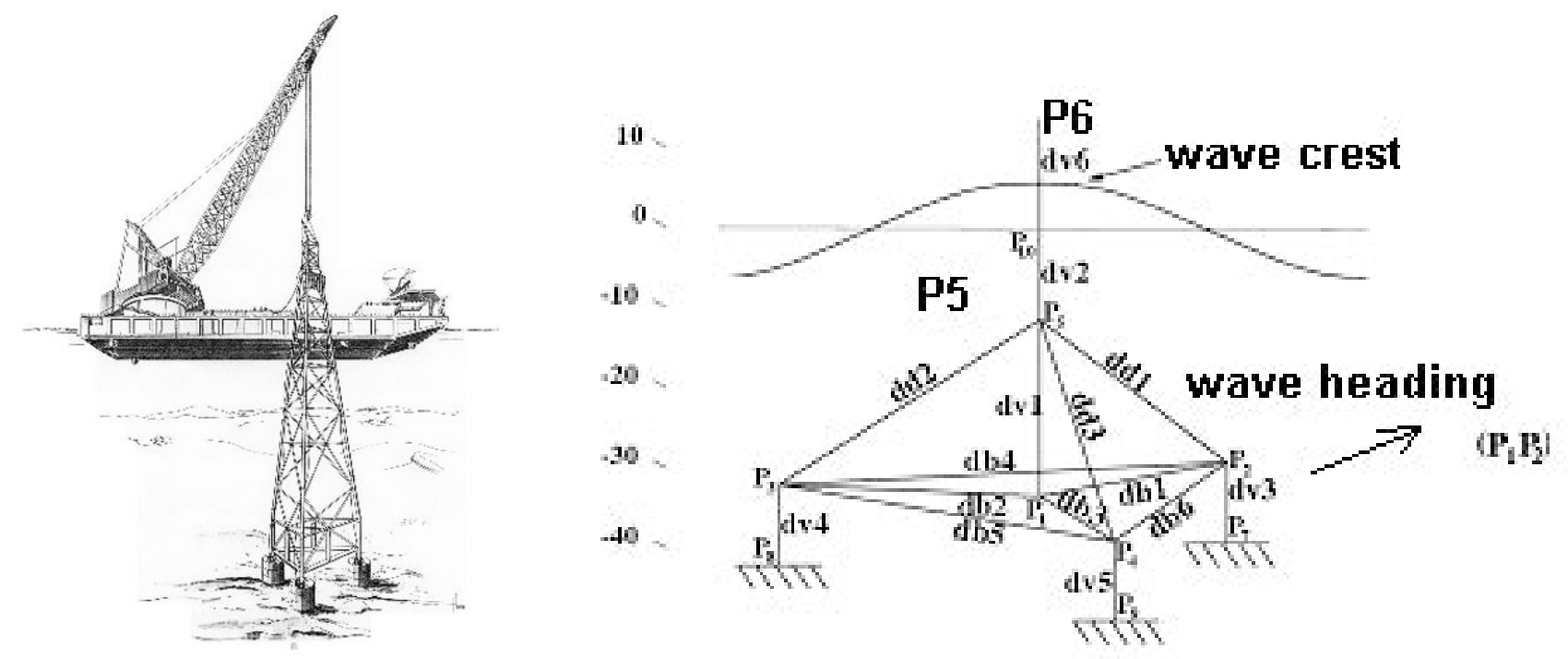

Figure 4. Tripod structure and finite element model of the studied structure 
In view to reduce computing costs, no call to an external FE software is realized. All structural analysis, CJFE model programming, pre/post-processing and computing of stochastic field of loading are made with Matlab software.

\subsection{Description of random variables}

Probability density functions, conditioning between variables, coefficients of variations (c.o.v) and truncatures of samples to keep simulated events in physical supports are presented in Table 1. They refer to severe environmental conditions (storm) in the Frigg field, near Shetland Islands in North Sea (Doucet et al., 1987). Simulations are performed with Modified Latin Hypercube Sampling: it consists in selection of events in the middle of iso-likely intervals.

Table 1. Characteristics of basic random variables

\begin{tabular}{|l|l|l|l|ll|}
\hline Basic variables & Distribution & Conditioning & c.o.v & Truncature & \\
\hline H, extreme wave height & Gumbel & $\left(\mathrm{H}_{\mathrm{s}}, \mathrm{T}_{\text {stat }}, \theta\right)$ & $8 \%$ & {$[\mathrm{~m}-2 \sigma ; \mathrm{m}+5 \sigma]$} & \\
\hline T, extreme wave period & Log-Normal & $\mathrm{H}$ & $10 \%$ & {$[\mathrm{~m}-\mathrm{k} \sigma ; \mathrm{m}+\mathrm{k} \sigma]$} & $\mathrm{k}=3$ \\
\hline $\begin{array}{l}\text { Coefficients } \mathrm{C}_{\mathrm{D}}, \mathrm{C}_{\mathrm{M}}, \mathrm{C}_{\mathrm{X}}, \\
\mathrm{C}^{\prime}{ }_{\mathrm{X}},\end{array}$ & Normal & - & $35 \%$ & {$[\mathrm{~m}-\mathrm{p} \sigma ; \mathrm{m}+\mathrm{p} \sigma]$} & $\mathrm{p}=2$ \\
\hline Crack length $a$ & Exponential & - & $35 \%$ & {$[-; 2 \pi \mathrm{R}]$} & \\
\hline
\end{tabular}

Where $H_{s}, T_{\text {stat }}, \theta$, denote respectively the significant wave height, the sea state duration and the wave heading. The hypothesis of exponential distribution for crack length " $a$ " comes from statistical analysis of inspection results in North Sea (Moan et al., 1997) and is extended here to the case of large cracks only; the upper bound for truncature is deduced from geometrical considerations (tube perimeter).

\subsection{Computation of probability of failure}

Reliability estimation is carried out by Monte-Carlo simulations. Two limit states are considered. The first one is based on the displacement $U_{6}$ at the top of the structure (node P6), the critical value (here $0.041 \mathrm{~m}$ ) being motivated by the maximal curve of the gas pipe attached to this vertical component. The second one considers the strain energy of the structure $E_{s}$, and aims to reflect the structural integrity. In this case, the critical value of the strain energy is more complex to define; it can be associated to a percentage of the strain energy of the non-cracked structure (Schoefs et al., 2003) or to another critical quantity. We suggest this last way. We present on Figure 5 the realizations of the couples $\left(U_{6}, E_{s}\right)$ that have been obtained under random loading on the non-cracked tripod structure. The fitting of 
this behavior (curve on the Figure 5) gives an average relationship between $U_{6}$ and $E_{s}$; a critical value $E_{c}$ of $2.9910^{4} \mathrm{~N} . \mathrm{m}$ is then deduced. It corresponds to the critical displacement $U_{c}$ of $0.041 \mathrm{~m}$. This value is deduced from the yield stress in the gaz pipe due to a deflection of the gaz pipe that is fixed on the structure.

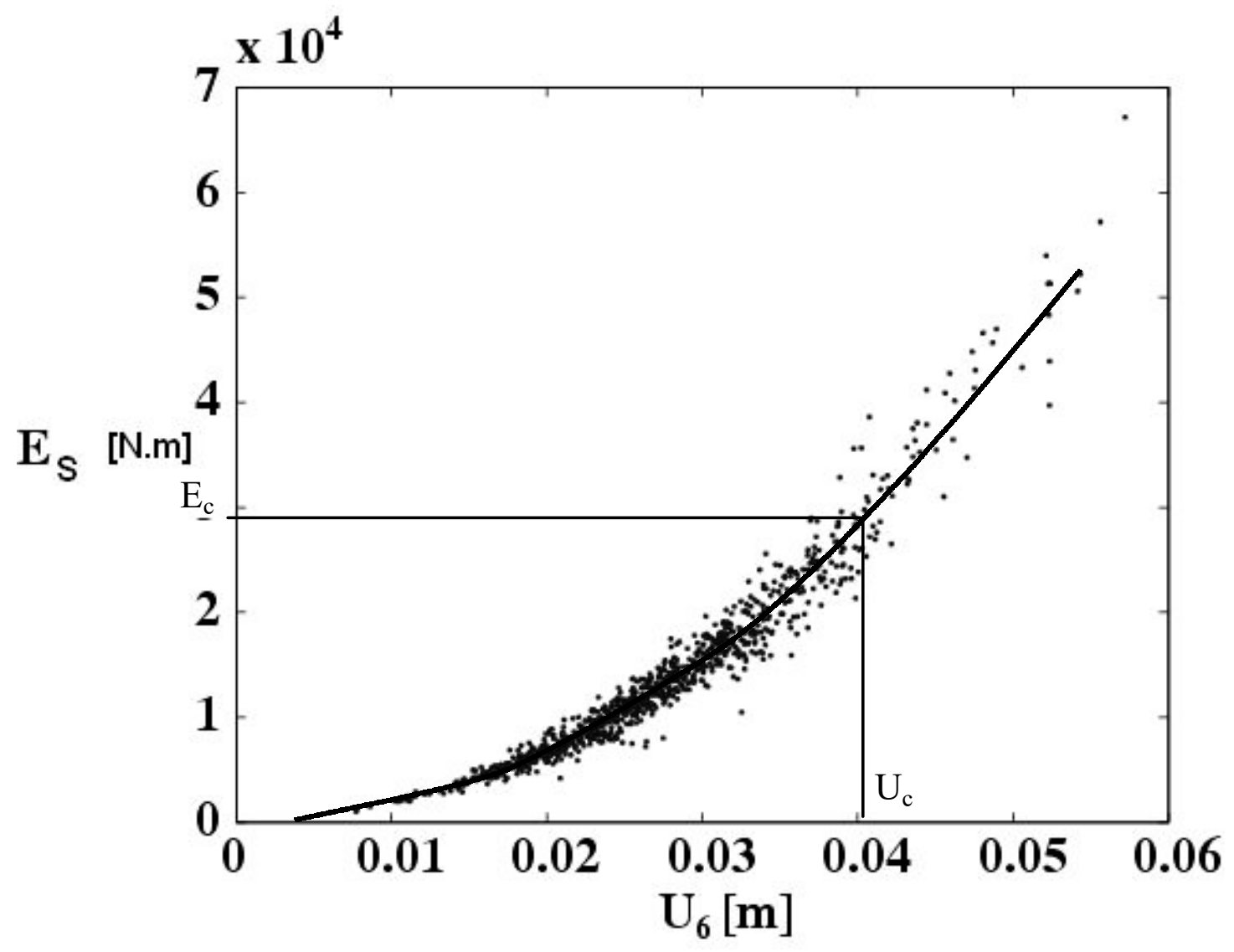

Figure 5. Realization of couples $\left(U_{6}, E_{s}\right)$; non-cracked tripod structure loaded with random waves

The limit states take the usual form of safety margins:

$$
\begin{gathered}
G_{U}=U_{c}-U_{6} \\
G_{E s}=E_{c}-E_{s}
\end{gathered}
$$

For a though crack of half-open angle $\varphi$ located on node P5 and which axis of symmetry makes an angle $\psi$ with the wave heading P1P2 (Figure 4), results of failure probability computation are plotted on Figure 6 for several configurations. Note that we assume for this study the wave heading to be deterministic because of storm conditions that are studied here. 

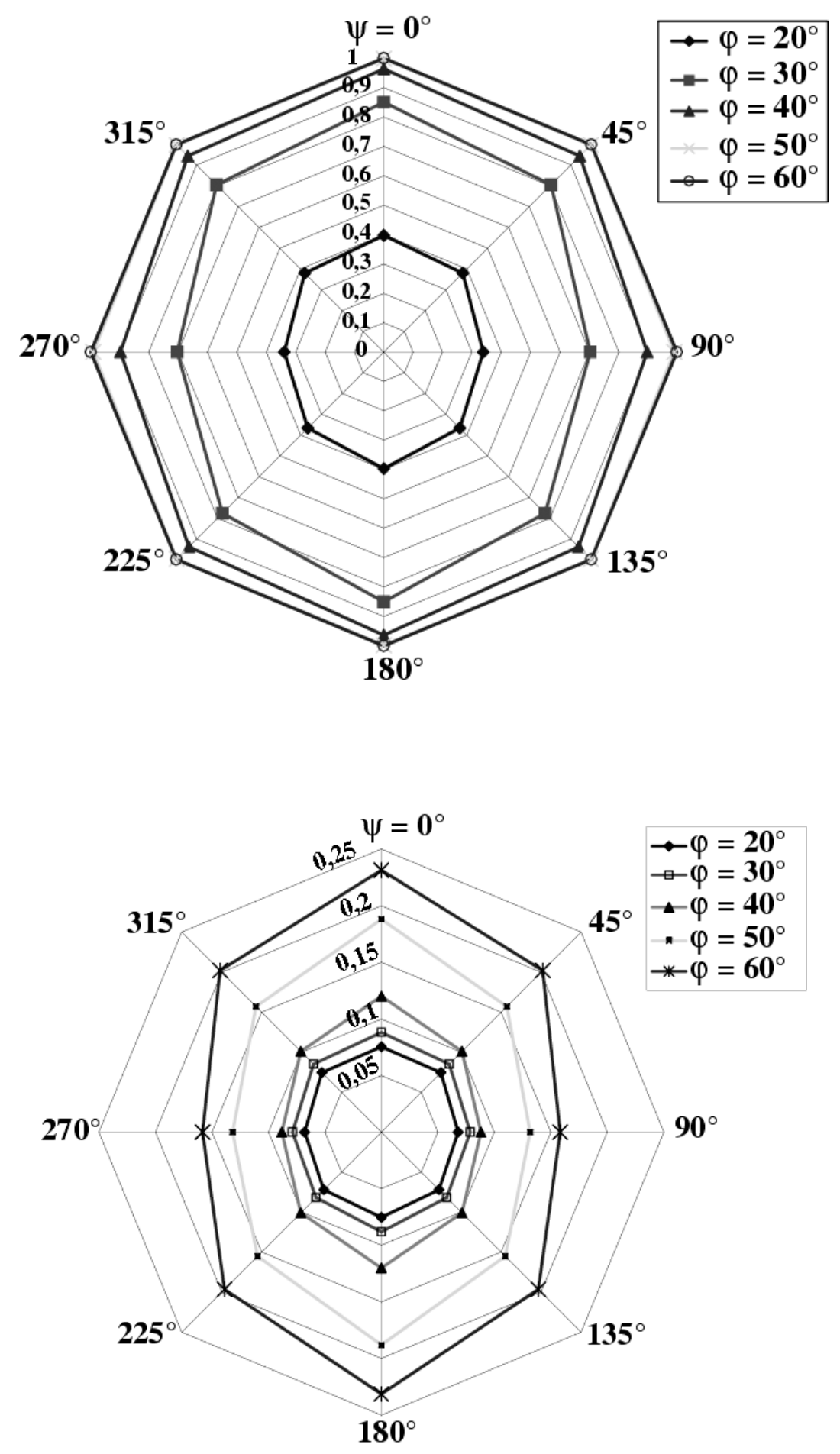

Figure 6. Probability of failure as a function of angle $\varphi$ and crack location $\psi$ for the displacement (up) and strain (down) safety margins

We note first that axis $0^{\circ}$ is an axis of symmetry for these curves: it can be explained by the symmetry in mechanical behavior, wave heading being deterministic and in the plane of symmetry of the structure and CJFE model being symmetric and bi-lateral. Then, despite of the selection of equivalent bounds in the sense of Figure 5, values of probability of failure obtained with the two limit state functions are very different: there is a factor of 5.25 for an half open angle of $20^{\circ}$ (from 0.0754 to 0.397 respectively for the strain and displacement safety margins). Moreover, their evolution with $\varphi$ and $\psi$ are different too. It underlines the need of 
improved limit state when performing risk analysis where absolute values can be looked for. In the following, displacement criterion only will be addressed.

\section{Modeling of inspection results}

\subsection{Definition}

Due to harsh conditions of inspection for divers, inspection results are often modeled in a probabilistic way: in fact wave shaking, current velocity, turbidity and weight of equipment introduce uncertainties and remove on site conditions from test in laboratory. We used here a bayesian definition of inspection results in terms of detection (Rouhan et al. 2003). It is based on the probabilities of 4 events:

$E_{1}$ : no presence of crack, conditional to no crack detection;

$E_{2}$ : absence of crack, conditional to crack detection;

$E_{3}$ : presence of crack, conditional to no crack detection;

$E_{4}$ : presence of crack, conditional to crack detection.

Let us denote by " $X$ ", the event "crack presence" which takes value 0 in case of absence and 1 in case of presence. We show that the probability associated to these events can be expressed as a function of the Probability of Detection $(\mathrm{PoD}=P(d(X)=1 \mid X=1))$, the probability of false alarm $(\mathrm{PFA}=P(d(X)=1 \mid X=1))$ and the probability of crack presence $(\gamma=P(X=1))$. Equations [6] and [7] give expressions for $P\left(E_{2}\right)$ and $P\left(E_{3}\right)$. Note that " $\gamma$ " is a stochastic process indexed with time and that depends on initial conditions of building, thermal and mechanical fatigue process and incidents: most of these effects are still not understood and modelled in offshore field. We consider the structure at a given time and here " $\gamma$ " is fixed at value 0.1 which corresponds to an estimation of the probability to observe large cracks assumed to be through cracks. Sensitivity studies are available in (Rouhan et al., 2003). The parametric surface $P\left(E_{2}\right)$ is drawn on Figure 7.

$$
\begin{aligned}
& P\left(E_{2}\right)=P(X=0 / d(X)=1)=\frac{P F A(X)(1-\gamma)}{P o D(X) \gamma+P F A(X)(1-\gamma)} \\
& P\left(E_{3}\right)=P(X=1 / d(X)=0)=\frac{(1-P o D(X)) \gamma}{(1-P o D(X)) \gamma+(1-P F A(X))(1-\gamma)}
\end{aligned}
$$

ROC curves (receiver operating characteristic) characterized the performance of the technic and human chain "NDT tool - acquisition and treatment - diver inspector" and link the PoD and the PFA for a given crack size. To estimate the probabilities [6] and [7], given a ROC curve, a projection of this curve on the surface $P\left(E_{i}\right)$ is realized and presented on Figure 7 for $P\left(E_{2}\right)$ and two ROC curves. 
Three ROC curves are plotted one on Figure 8 for three techniques, for the detection of a crack of half open angle $20^{\circ}$.

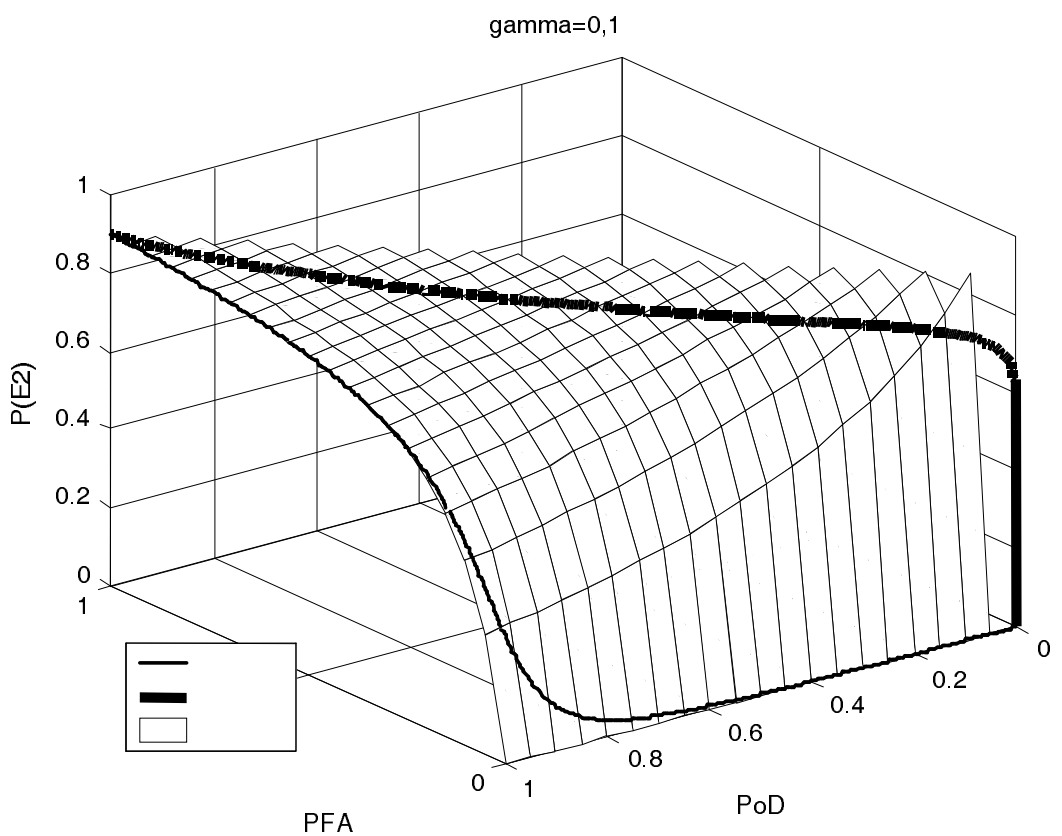

Figure 7. $P\left(E_{2}\right)$ associated to ROC curves ROC 1 and ROC 2

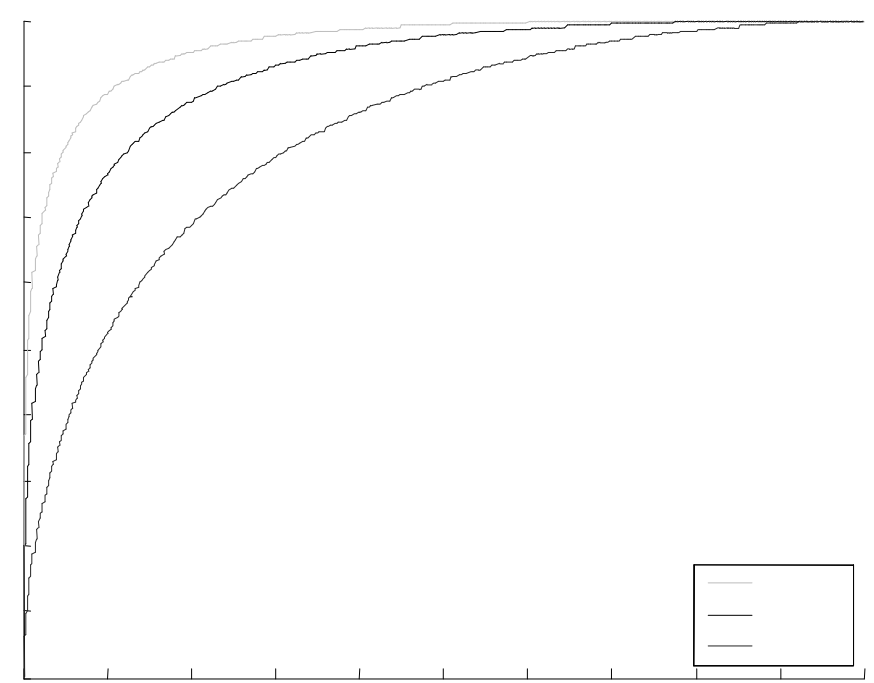

Figure 8. ROC curves corresponding to three NDT techniques

Due to the uncertainty on No-Destructive-Technique (N.D.T) in situ performance, we suggest here to compute $m\left(P\left(E_{i}\right)\right)$ the expectation of $P\left(E_{i}\right)$ along the ROC curve [8].

$$
\left.\mathrm{m}\left(\mathrm{P}\left(\mathrm{E}_{\mathrm{i}}\right)\right)\right|_{\mathrm{ROC}}=\left.\frac{1}{\mathrm{~L}_{\mathrm{ROC}}} \int_{\mathrm{ROC}} \mathrm{P}\left(\mathrm{E}_{\mathrm{i}}\right)\right|_{\mathrm{ROC}} \mathrm{dl}_{\mathrm{ROC}}
$$


where $l_{R O C}$ is the curvilinear abscissa along the projected ROC curve on $P\left(E_{i}\right)$ surface, $L_{R O C}$ the length of ROC curve in (PoD, PFA) plane and $\left.\mathrm{P}\left(\mathrm{E}_{\mathrm{i}}\right)\right|_{\mathrm{ROC}}$ value of $P\left(E_{i}\right)$ at this abscissa.

The expectations of the probability for events $E_{2}$ and $E_{3}$ are computed for the three ROC curves plotted on Figure 8 and presented in Table 1 with $\gamma$ equals 0.1 . These values are decreasing with the performance of the N.D.T from ROC 3 to ROC 1.

Table 2. Expectations of the probability $P\left(E_{2}\right)$ and $P\left(E_{3}\right)$ for three ROC curves

\begin{tabular}{|c|c|c|c|}
\hline & \multicolumn{3}{|c|}{$\gamma=0.1$} \\
\hline & ROC 1 & ROC 2 & ROC 3 \\
\hline $\mathrm{m}\left(\mathrm{P}\left(\mathrm{E}_{2}\right)\right)$ & 0.396 & 0.4675 & 0.683 \\
\hline $\mathrm{m}\left(\mathrm{P}\left(\mathrm{E}_{3}\right)\right)$ & 0.0269 & 0.0296 & 0.0417 \\
\hline
\end{tabular}

\subsection{Risk functions and results}

In terms of risk estimation, based on economic criteria only, the over-cost $\overline{E(C)}_{d}$ due to a bad decision (events $E_{2}$ and $E_{3}$ ) and the cost in case of no detection $E(C)_{n d}$ are then expressed in Equations [9] and [10]. These costs are function of the probability of $P\left(E_{2}\right)$ and $P\left(E_{3}\right)$ and the costs of inspection, repair and failure.

$$
\begin{aligned}
& \overline{E(C)}_{d}=\left.\left(C_{\text {inspection }}+C_{\text {repair }}\right) m\left(P\left(E_{2}\right)\right)\right|_{R O C} \\
& E(C)_{\text {nd }}=C_{\text {inspection }}+\left.C_{\text {failure }} P_{f \mid E_{3}} m\left(P\left(E_{3}\right)\right)\right|_{R O C}
\end{aligned}
$$

where $P_{f \mid E_{3}}$ is the probability computed in 4.3, and knowing the inspection and repair policy:

- no detection leads to no repair and consequently to a risk of failure,

- a detection leads to a repair.

In this last case, the failure is not considered because the risk of failure is of second order: only the over-cost (Equation [9]) due to a bad decision is taken into account. Let us used the dimensionless parameters $c_{1}=c_{i} / c_{r}$ and $c_{2}=c_{r} / c_{f}$, we suggest a parametric analysis that allows to introduce the inspection $\cos c_{i}$ divided by the cost of repair $c_{r}$ and which takes values in the range [0;1], and the 
cost of repair divided by the cost of failure $c_{f}$ and which takes values in $[0 ; 0.1]$. The probability of failure $P_{f}$ is computed with the limit state function of Equation [4].

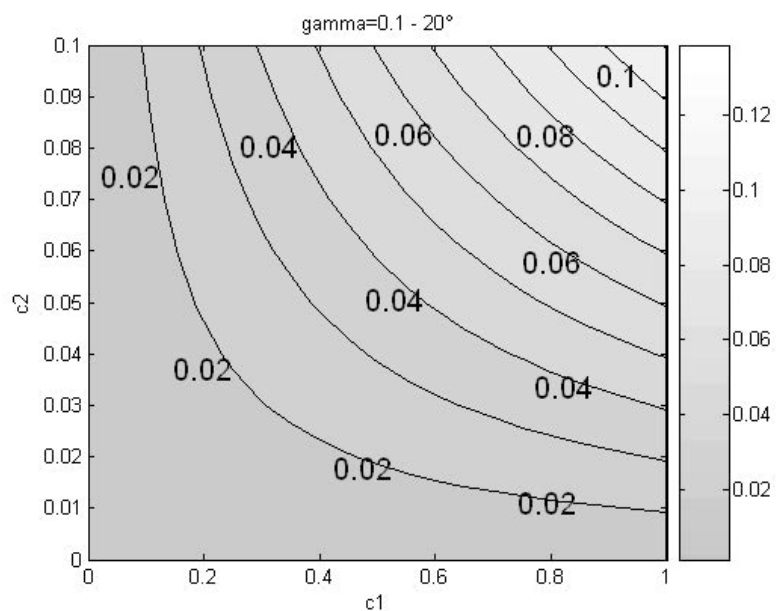

Evolution of $E(C)_{n d}$ for ROC 1

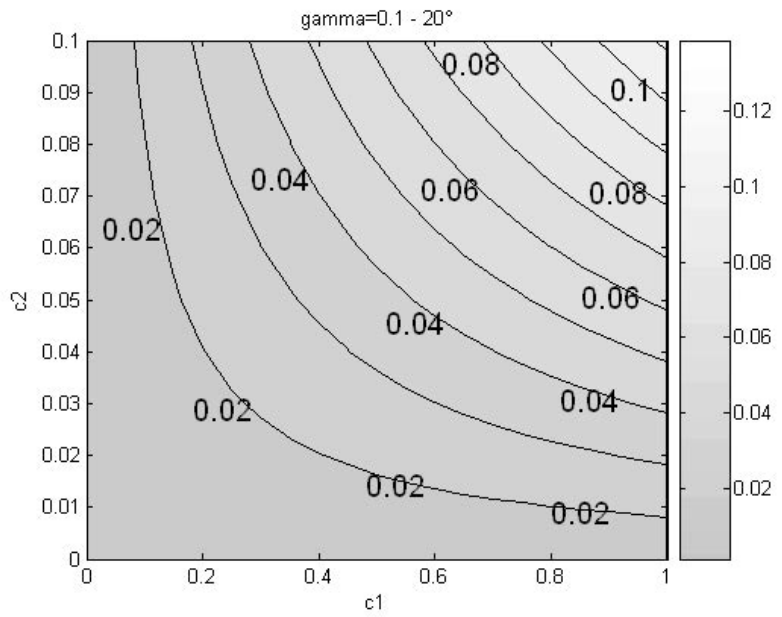

Evolution of $E(C)_{n d}$ for ROC 2

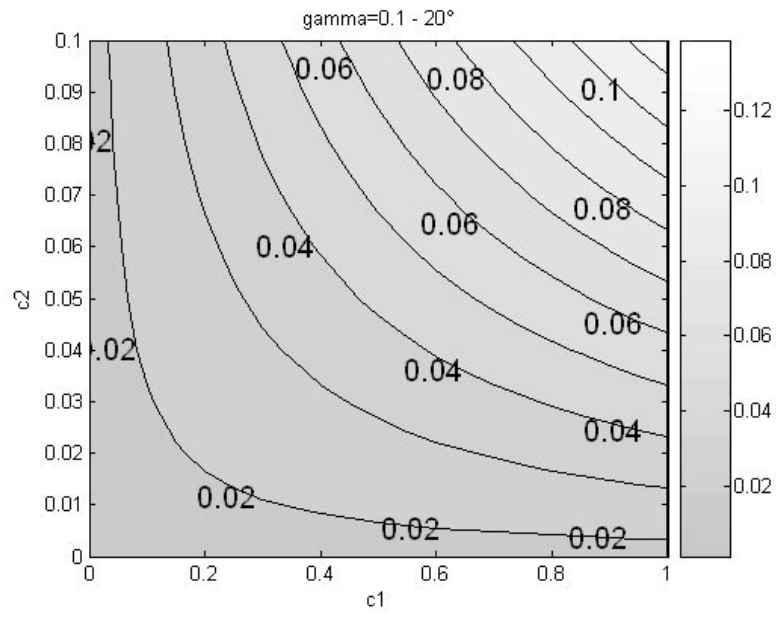

Evolution of $E(C)_{n d}$ for ROC 3

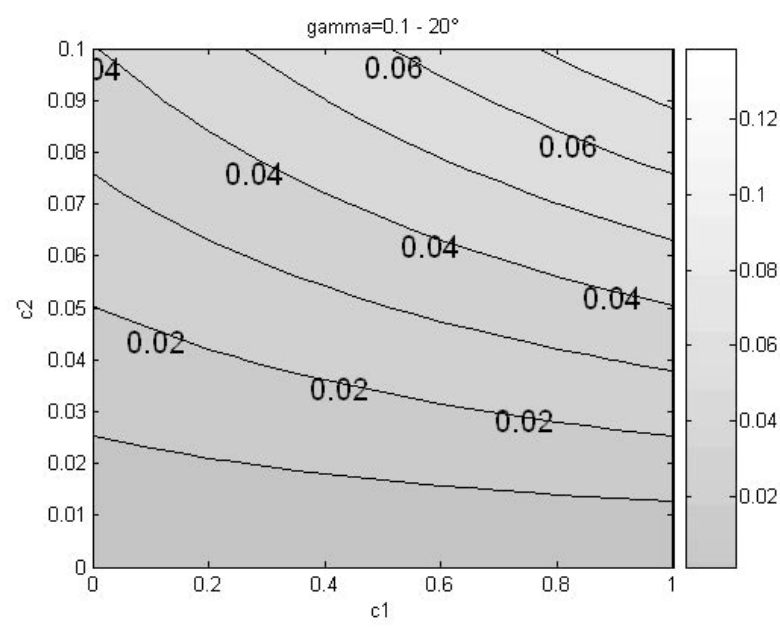

Evolution of $E(C)_{d}$ for ROC 1

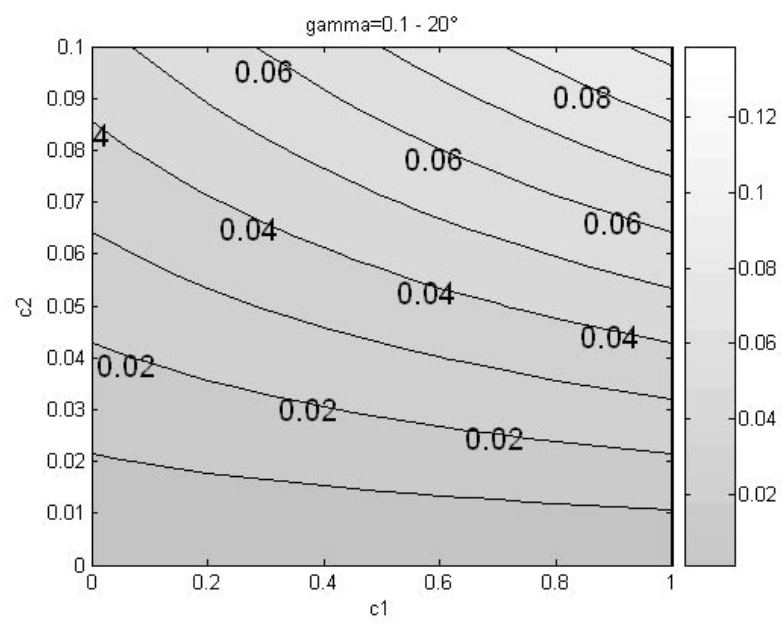

Evolution of $E(C){ }_{d}$ for ROC 2

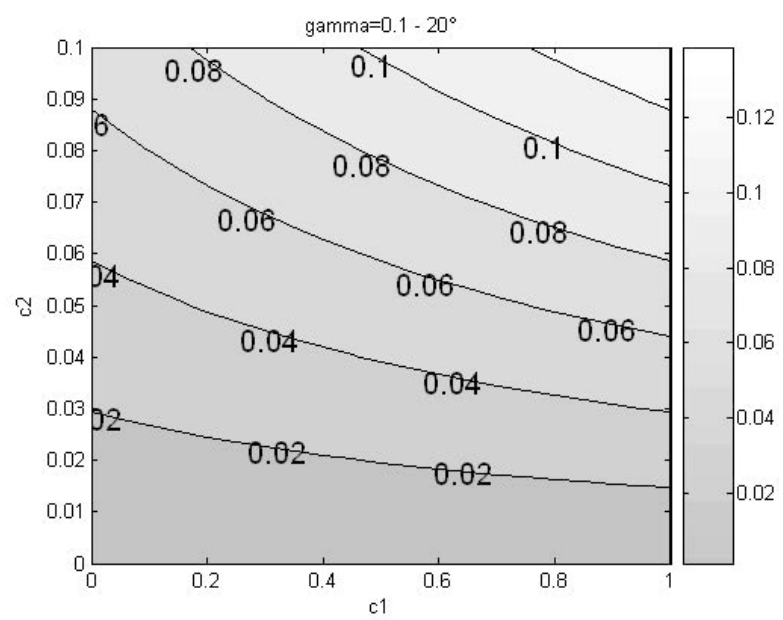

Evolution of $E(C){ }_{d}$ for ROC 3

Figure 9. Evolution of risk in case of no-detection (left side) or detection (right side) in the plane $\left(c_{1}, c_{2}\right)$ for half open angle $20^{\circ}$

Figure 9 presents curves of risk functions in case of detection (Equation [9]) and in case of no detection (Equation [10]) as functions of the couple of parameters 
$\left(c_{1}, c_{2}\right)$ when using the three CND techniques presented in Figure 8. An half-open angle of $20^{\circ}$ and a probability of crack presence " $\gamma$ " are selected for illustrations. In case of longer cracks, these risks increase but the trends and ranking of techniques are similar. The risk decreases clearly when increasing NDT performance, from ROC curve 3 to 1 . The over-cost in case of detection is lower than the risk in case of no detection. It appears that the evolution with parameters $c_{1}$ and $c_{2}$ are strongly non linear and lead to the conclusion that this analysis must be placed in a global cost study. In fact, at given level of $c_{2}$ and cost of repair, if NDT 1 is significantly more expensive than NDT 2 or 3, this one can be less attractive in terms of risk. A more complete study allows to introduce combination of NDT performance is available in (Schoefs et al., 2004).

\section{Conclusions}

This paper presents the several steps of a risk estimation in the case of cracked joint of offshore structures submitted to extreme wave loading:

- the response surface modeling of wave loading and mechanical behaviour,

- the selection of random variables,

- the reliability estimation,

- the hazards on length measurements and detection of cracks.

A safety margin based on the displacement of a specific node is compared to another one based on strain energy. It is shown that the corresponding level of probability of failure are different despite the selected critical values are linked. Only the limit state based on displacement is used for the risk analysis. Three techniques are then compared in terms of mean performance and are introduced in the risk analysis. A cost parametric study allows to select the best one when looking the costs of detection and non-detection.

Acknowledgements

The authors would like to acknowledge Ifremer and especially Benoît Bigourdan and Dominique Chocqeuse for their support of this work.

\section{Bibliography}

Bouyssy V., Rackwitz R., "Approximation of non-normal responses for drag dominated offshore structures", Reliability and Optimization of Structural Systems, proc. $6^{\text {th }}$, IFIP WG 7.5, Assisi, Italy, Chapman and Hall, 1994, p. 161-168.

Doucet Y., Labeyrie J., Thebault J., "Validation of stochastic environemental design criteria in the Frigg Field", Adv. Underw. Tech., SUT, 12, 1987, p. 45-59. 
Goyet J., Rouhan A., Faber M.H., "Industrial implementation of risk based inspection planning lessons learned from experience: Part 1: The Case of FPSO's", Proceedings of OMAE04, $23^{\text {rd }}$ International Conference on Offshore Mechanics and Arctic Engineering, OMAE2004-51572, June 20-25, Vancouver, Canada, 2004.

Kroon I.B., "Comparative risk assessment for decommissioning decision support", International Forum on Engineering Decision Making, First Forum December 5-9, Stoos, Switzerland, 2004.

Labeyrie J., Schoefs F., "A Discussion on response surface approximations for use in structural reliability", $6^{\text {th }}$ IFIP WG7.5, Reliability and Optimization of Structural Systems, $\mathrm{n}^{\circ}$ 15, Assisi, Italy, Chapman and Hall, 1994, p. 161-168.

Labeyrie J., Schoefs F., "Matrix Response Surfaces For Describing Environmental Loads", Vol. II: Safety and Reliability, Proc. $15^{\text {th }}$ International Conference on Offshore Mechanics and Arctic Engineering, Florence, 1996, p. 119-126.

Leira B.J., Holmås, Herfjord K., "Response surface parameterization for estimation of fatigue damage and extreme response of marine structures", ICASP'03, International Conference on Application of Statistics and Probability in Civil Engineering, Der Kiureghian, Madanat and Pestana eds, 2003 Millpress, Rotterdam, 2003, p. 589-597.

Lemaire M., "Finite element and reliability: Combinated methods by response surface", PROBAMAT-21 ${ }^{\text {st }}$ Century: Probability and Materials, $\mathrm{n}^{\circ}$ 46, 1997, p. 317-331.

Muzeau J.P., Lemaire M., Besse P., Locci J.M., "Evaluation of reliability in case of complex mechanical behaviour", Vol. II: Safety and Reliability, Proc. of $12^{\text {th }}$ Int. Conf. on Offshore Mechanics and Arctic Engineering, (OMAE'93), ASME 1993, p. 47-56.

Madsen H.O., "Stochastic modeling of fatigue crack growth and inspection", Probabilistic Methods For Structural Design, collection Solid Mechanics and its applications, Guedes Soares (Ed), Kluwer academic publisher, 1997, p. 59-83.

Moan T., Vårdal O.T., Hellevig N.C, Skjoldli, "In-service observations of cracks in north sea jackets. A study on initial crack depth and POD values", Vol. II: Safety and Reliability, Proceeding of $16^{\text {th }}$ International Conference on Offshore Mechanics and Arctic Engineering, (OMAE'97), New York ASME, editor 1997, p. 189-197.

Morison J.R., O'Brien M.P., Johson J.W., Schaff S.A., "The forces exerted by surfaces waves on piles", Petroleum trans., n 189,1950, p. 149-154.

Rguig M., Méthodologie des surfaces de réponse pour l'analyse en fiabilité des plates-formes pétrolières offshore fissurées, mémoire de thèse de doctorat, Nantes, 2005.

Rguig M., Schoefs F., «Modélisation par surface de réponse d'une structure fissurée : cas d'une plate-forme offshore», $17^{e}$ Congrès français de mécanique (CFM 2005), Université de Technologie de Troyes, 29 août-2 septembre 2005.

Rouhan A., Goyet J., Faber M.H., "Industrial Implementation of risk based inspection planning lessons learned from experience: Part 2: The case of steel offshore structures", Proceedings of OMAE'04, $23^{\text {rd }}$ International Conference on Offshore Mechanics and Arctic Engineering, OMAE2004-51573, Vancouver, Canada, June 20-25, 2004. 
Rouhan A., Schoefs F., "Probabilistic modelling of inspection results for offshore structures", Structural Safety, Elsevier Ltd. 2003, vol. 25, p. 379-399.

Schoefs F., Response surface modelling of wave loads in structural reliability analysis, $\mathrm{PhD}$ Dissertation, Nantes, 1996.

Schoefs F, Rguig M., Rouhan A., "Reliability of jacket platforms submitted to through cracks. Bridges and special structures", Proceeding of $9^{\text {th }}$ International conference on Applications of Statistics and Probability in Civil Engineering, (ICASP'03), July 6-9 2003, San Francisco, USA, vol. 2, Millpress Rotterdam, p. 1703-1710.

Schoefs F, Rguig M., Le Van A., «Fiabilité des structures tubulaires fissurées - transfert des non-linéarités par surfaces de réponse », CINM'2004, Colloque international des problèmes non linéaires en mécanique, Fès, Maroc, 24-26 mai 2004.

Schoefs F., Clément A., "Multiple inspection modelling for decision making and management of jacket offshore platforms: effects of false alarms", International Forum on Engineering Decision Making, Stoos, Switzerland, December 5-9, 2004.

Schoefs F., Rguig M., Le Van A., "Response surface methodology for evaluation of reliability for jacket platforms submitted to through cracks", Proc. of the Ninth International Conference on Structural Safety and Reliability, Track 3 Offshore structures, wind, geotechnical 3, ICOSSAR'05, Millpress Science Publishers, Rome, Italy, June 19-23, 2005, p. 1325-1332.

Wenche K. Rettedal, Terje Aven, Ove T. Gudmestad., "Integrating QRA and SRA methods within a Bayesian framework when calculating risk in marine operations: two examples", Journal of Offshore Mechanics and Arctics Engineering, 2000, vol. 122, p. 181-187. 